\title{
WP3-Innovation in Agriculture and Forestry Sector for Energetic Sustainability
}

\author{
Andrea Colantoni * ${ }^{\circledR}$, Rodolfo Picchio*, Alvaro Marucci ${ }^{\circledR}$, Elena Di Mattia, Valerio Cristofori ${ }^{\circledR}$,

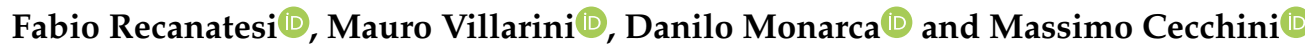 \\ Department of Agricultural and Forestry Sciences (DAFNE), University of Tuscia, via S. Camillo De Lellis, \\ 01100 Viterbo, Italy; marucci@unitus.it (A.M.); dimattia@unitus.it (E.D.M.); VALERIO75@UNITUS.IT (V.C.); \\ fabio.rec@unitus.it (F.R.); mauro.villarini@unitus.it (M.V.); monarca@unitus.it (D.M.); cecchini@unitus.it (M.C.) \\ * Correspondence: colantoni@unitus.it (A.C.); r.picchio@unitus.it (R.P.); Tel.: +39-0761357356 (A.C.)
}

Received: 15 September 2020; Accepted: 22 October 2020; Published: 16 November 2020

check for updates

\section{Documents in This Special Issue}

Papers submitted and published in this Special Issue "WP3-Innovation in Agriculture and Forestry Sector for Energetic Sustainability" bring together some of the latest research results in the field of biomass valorization and the process of energy production and climate change and other items about energetic sustainability [1-20]. Moreover it is very important to evaluate the safety aspects for energy plant use [21-24].

Responses to our call generated the following statistics:

- Submissions (21);

- Publications (15);

- Rejections (6);

- Article types: research articles (13), reviews (2).

Published submissions are related to 15 published articles.

We found the edition and selections of papers for this exercise very inspiring and rewarding. We also thank the editorial staff and reviewers for their efforts and help during the process.

For better comprehension, the contributions to this special issue are split in parts, as follows.

\subsection{Research Articles}

The first contribution in this section explores the Performance Assessment of Front-Mounted Beet Topper Machine for Biomass Harvesting by Volodymyr Bulgakov, Simone Pascuzzi, Semjons Ivanovs, Francesco Santoro, Alexandros Sotirios Anifantis and Ievhen Ihnatiev. In this article, the authors focused their attention on the analysis of performance related to the operation of a new high-quality prototype of sugar beet top harvester that they built in Ukraine. Sugar beet is an extensive crop of of great agronomic value with significant productive and economic returns and Ukraine's sugar beet accounts for about $5.1 \%$ of the overall world production. Sugar beet and the by-products resulting from its manufacturing transformation are a significant renewable energy resource; a top sugar beet harvester, front-mounted on a tractor, was built by the authors in Ukraine. After the description of the beet topper machine features, the field tests, which took place in the Kiev region, were presented with reference to the tractor traction power using sensors able to measure torque and angular speeds. The experimental data were processed and showed that the energy costs related to the single work row of the prototype beet top harvesting machine were significantly lower than the corresponding performance parameter values of beet top-harvesting machines currently in use in Ukrainian farms. 
The second paper is entitled Environmental and Economic Analysis of an Anaerobic Co-Digestion Power Plant Integrated with a Compost Plant and has been written by Sara Rajabi Hamedani, Mauro Villarini, Andrea Colantoni, Maurizio Carlini, Massimo Cecchini, Francesco Santoro and Antonio Pantaleo. The article presents an analysis of economic and environmental issues of anaerobic digestion power-generation plants considering the Italian market evolution and basedon the scenario of a real case study. The spread of anaerobic digestion power plants slowed down after the remarkable growth that occurred between 2009 and 2016. The specific analysis considers also the benefits of use of digestate as fertilizer and of cogeneration heat in order to exploit all the resources potentially coming from these systems. Furthermore, a life-cycle analysis (LCA) has been carried out and the unreleased environmental emissions were converted into economic benefits by means of a stepwise approach. The final results of the analysis showed that the integration of a compost plant within the biogas plant integrated in the Italian electricity grid regulation allowed it to reach good financial performance in terms of IRR (internal rate of return) and NPV (net present value).

The third article entitled "The techno-economic modelling of biomass pellet routes: feasibility in Italy" was written by Antonio Pantaleo, Mauro Villarini, Andrea Colantoni, Maurizio Carlini, Francesco Santoro and Sara Rajabi Hamedani. Wood and agricultural biomass pellets boost the potential of bio-fuels for power production in tertiary and residential sectors. The production of pellets, however, is a multi-stage process where the supply-processing phases and the overall energy input strongly depend on the characteristics of the input biomass. In this paper, a model to evaluate the economic issues of agro-pellet was developed. The breakdown structure of costs has been represented after having described the manufacturing process from raw biomass to finished pellet. CAPEX and OPEX have been determined by means of a mathematical model. In the CAPEX, pelletizing, drying, pretreatment storage plants in addition to installation and engineering costs have been considered. The annual operation and maintenance costs have been calculated considering the following expense items: raw biomass supply and transport, biomass drying, electricity consumption, plants maintenance and personnel. After the model implementation, the analysis was applied to the case study of an Italian firm producing doors and windows in laminated wood. The analysis was then carried out within 4 different scenarios where the organization and, especially, the origin of the biomass used for the pellet production changes. The best scenario is the second one in which all the biomass treated comes from the production process of the company. Finally, the result showed that use of forestry residues with high moisture and high ash content, high costs of collection/transport, and high costs of pre-treatment and drying is not financially competitive.

The fourth papers entitled Evaluation of Compressor Heat Pump for Root Zone Heating as an Alternative Heating Source for Leafy Vegetable Cultivation has been written by Chiara Terrosi, Sonia Cacini, Gianluca Burchi, Maurizio Cutini, Massimo Brambilla, Carlo Bisaglia, Daniele Massa and Marco Fedrizzi. It aims to investigate the best value heating system for protected horticulture represented by leafy vegetable cultivation with a focus on the performance of the heat pump. It used 840 sweet basil seedlings during the experimental tests within the case study. The three systems examined were a condensing boiler, a heating pump and a air-to-air heater. The purpose was to verify the applicability considering the moderate temperature achieved by this system and the energy efficiency considering the absence of electricity, produced from renewable energy resources, to feed the heat pump itself. The heating distribution was described and the results presented showing that an optimization of the system can be achieved by reducing energy needs, using energy more efficiently and using less expensive energy sources. In particular, the adoption of an electric heat pump for greenhouse heating allows remarkable energy savings to be obtained and, especially, with respect to the condensing boiler and the air heater, the energy reduction amounts to $45 \%$.

The fifth article entitled Influence of Oxidant Agent on Syngas Composition: Gasification of Hazelnut Shells through an Updraft Reactor has been written by Francesco Gallucci, Raffaele Liberatore, Luca Sapegno, Edoardo Volponi, Paolo Venturini, Franco Rispoli, Enrico Paris, Monica Carnevale and Andrea Colantoni. This work concerns a laboratory test at Sapienza University of Rome of an 
updraft gasifier reactor fed with hazelnut shells, profitably used as fuel in thermo-chemical processes, such as direct combustion or gasification. The tests were aimed to study the effect of an oxidant agent on syngas quality (namely its lower heating value), composition, producible energy, and cold gas efficiency. Then, temperature distribution, syngas composition and heating value, and producible energy were measured. The syngas flow produced by the two different oxidant agent, air and steam, was roughly the same but its quality was considerably different. This different performance can be notice by the following results: syngas produced by steam gasification had a lower heating value of 13.1 MJ/ $\mathrm{Nm}^{3}$ with an energy flow of $5.4 \mathrm{MJ} / \mathrm{s}$. On the contrary, the syngas produced by air gasification had a lower heating value of less than $6 \mathrm{MJ} / \mathrm{Nm}^{3}$ with a $3.3 \mathrm{MJ} / \mathrm{s}$ energy flow.

The sixth article entitled Sustainability Assessment of Alternative Strip Clear Cutting Operations for Wood Chip Production in Renaturalization Management of Pine Stands was written by Janine Schweier, Boško Blagojević, Rachele Venanzi, Francesco Latteriniand Rodolfo Picchio. The object of this paper is a sustainability impact assessment approach was applied to understand how to modify forest operation planning in order to minimize environmental impact.

The work highlights the urgent exigence to apply silvicultural management strategies in order to support vegetation dynamics and enhance stand ecology, like the renaturalization concept. The forest operations are essential with respect to the environmental issues of this topic and sustainable forest management should be implemented. The objective of the forest operations presented by this work was that the forest wood chains could support the aforementioned strategy of renaturalization in typical afforested pine plantations in the Mediterranean basin. Considering the plethora of factors and criteria, often conflicting, to be considered, a multi-criteria decision analysis was applied. Three different forest wood chains were applied in pine plantations, all differing in the extraction system (animal, forestry-fitted farm tractor with winch, and double drum cable yarder). Twelve economic, environmental and socio-ecological indicators were selected and calculated in order to address the sustainability assessment. After that a multi-criteria decision analysis has been implemented. Results showed that first ranked alternative was case 2, in which extraction was conducted by a tractor with a winch. The main reason was that this alternative had best performance for $80 \%$ of the analyzed criteria.

The seventh paper is entitled Production of Wood Pellets from Poplar Trees Managed as Coppices with Different Harvesting Cycles and was written by Vincenzo Civitarese, Andrea Acampora, Giulio Sperandio, Alberto Assirelli and Rodolfo Picchio. This article aims to study high-density biomass plantations and the particular case short rotation wood coppice of poplar has been focused on and, by means of the CREA farm, was exploited to develop the experimental activity using different treatments with harvesting cycles of 3, 6 and 9 years. The objective of the study was to identify the best raw material suitable for pellet production from trees or stems. The crops were subdivided by crop cycle and type of product in six groups separately stored in six bins after having been chipped and refined. Then, dehydration and pelletization the moisture content was measured in three different times. During the monitoring process, the crops were sized and the dehydration process controlled. The pelletizing process using high density poplar plantation as a raw material highlights the possibility of obtaining a product that meets many of the quality standards required on the market.

The eighth article is entitled Optimizing the 3D Distributed Climate inside Greenhouses Using Multi-Objective Optimization Algorithms and Computer Fluid Dynamics and was written by Kangji Li, Wenping Xue, Hanping Mao, Xu Chen, Hui Jiang and Gang Tan. This work focuses on greenhouses considered important for densely-populated regions. Then, the modelling of the micro-climate of greenhouses by means of a hybrid computational fluid dynamics -evolutionary algorithm was implemented. The objective was to determine the optimal combination of parameters in order to make the crops grow and corresponding to the Pareto frontier. To that aim, a commercial greenhouse located in China was used for the validation of the aforementioned model. Then, after the model construction, it was validated with a field experiment. The temperature was measured and compared with values determined by the model. Afterwards, the optimization process was based on the following 
two problems: first, how to find out multiple variables' optimal setting points according to multiple environmental requirements; and second, for local planting areas, how to adjust environmental variables with high spatial resolution to find the balance of energy saving and environment suitability. Twenty five pairs of control variables from a total of 250 chromosomes were identified belonging to the optimum set point basis. This way, the optimal tradeoff between energy efficiency and environmental suitability was determined. A detailed analysis may be provided that helps find the potential of the crop yield and energy conservation.

Moreover, other articles published in this special issue are:

Oscillations Analysis of Front-Mounted Beet Topper Machine for Biomass Harvesting by Volodymyr Bulgakov, Simone Pascuzzi, Alexandros Sotirios Anifantis and Francesco Santoro. The goal of this study was to assess the opportunity to use beet leaves and tops for the production of renewable energy. In this regard, one of the main issues is related to harvesting operation and waste recovery. In particular, considering the mechanization applied and the natural soil roughness, the machines are affected by angular oscillations in a longitudinal-vertical plane that strongly affect the cutting uniformity. Using Lagrange II-type equations some simulations were performed to assess the design and kinematic parameters of a front-mounted beet topper. According to the main findings, in order to improve the efficiency of this harvesting machine, soil preparation is first needed, while the influence of the stiffness and damping parameters of the feeler wheels pneumatic tires is not so clear.

Life Cycle Assessment and Environmental Valuation of Biochar Production: Two Case Studies in Belgium by Sara Rajabi Hamedani, Tom Kuppens, Robert Malina, Enrico Bocci, Andrea Colantoni and Mauro Villarini. This paper aimed to understand the economic feasibility of biochar production. Currently, the biochar production process may not be considered very cheap, hence it is difficult to find lenders and business owners. In this initial phase, other aspects need to be carefully assessed, mainly related to two of the sustainability pillars, social and environmental. These issues were assessed through life-cycle analysis (LCA) performed for two potential biochar production systems and two different feedstocks: willow and pig manure. The functional unit was one ton of biochar and the LCA database was SimaPro. The findings showed that the biochar production from willow achieves better results for all environmental impact categories surveyed in comparison to biochar from pig manure. Also, a monetary valuation was applied in order to weigh environmental benefits against environmental costs using the Ecotax, Ecovalue, and Stepwise approach. The final remarks highlight once again that willow biochar is preferable to biochar production from pig manure from the environmental point of view.

The last two research articles are:

Wood Chip Drying through the use of a Mobile Rotary Dryer by Angelo Del Giudice, Andrea Acampora, Enrico Santangelo, Luigi Pari, Simone Bergonzoli, Ettore Guerriero, Francesco Petracchini, Marco Torre, Valerio Paolini and Francesco Gallucci. One of the main problems related to biomass use for energy production is the moisture content. Generally, moisture content negatively affects the energy conversion efficiency and the feedstock storage. For a number of issues, biomass drying is a crucial operation in which technology has tried in various ways to solve the most critical aspects. Currently, rotary dryers seem to be the best solution, concerning low cost of maintenance and consume of $15 \%$ and $30 \%$ less in terms of specific energy. This paper focused on the use of a new prototype of mobile rotary dryer concurrent flow on wood chips and three wooden biomass typologies have been assessed (Populus spp., Robiniapseudoacacia L. and Vitis vinifera L.). The drying process was affected by the initial moisture content: poplar in $8 \mathrm{~h}$ from $50 \%$ reached $41 \%$; black locust in $6 \mathrm{~h}$ from $30 \%$ reached $21 \%$; grapevine in $6 \mathrm{~h}$ from $30 \%$ reached 21\%. Moreover, this study showed that other biomass characteristics (particle size distribution and bulk density) have an influence on drying operation and as a consequence on the process energy consumption. Findings showed that the three-biomass needed 1.61 (poplar), 0.86 (grapevine), and $1.12 \mathrm{MJ} \mathrm{kg} \mathrm{dry} \mathrm{solids}{ }^{-1}$ (black locust), with an efficiency of thermal drying ( $\eta$ ) respectively of $37 \%, 12 \%$, and $27 \%$. From this work some suggestions were formulated in order to improve the sustainability of the process: the need to increase the efficiency of the thermal 
insulation of mobile dryer; the application of the mobile dryer in small-farms, and using exhaust gases from thermal power plants.

The final article is entitled: Sensitivity Analysis of Different Parameters on the Performance of a CHP Internal Combustion Engine System Fed by a Biomass Waste Gasifier by Mauro Villarini, Vera Marcantonio, Andrea Colantoni and Enrico Bocci. This paper presented a study on the energetic valorization of residues from biomasses production. The energy production or proper conversion was undertaken through gasification and then by using an internal combustion engine with a generator. Sampling was undertaken selecting the most representative types of biomass waste from agricultural productions, and the most suitable one to be used in the gasification process. Generally, good quality syngas with up to $16.1 \% \mathrm{CO}-4.3 \% \mathrm{CH}_{4}-23.1 \% \mathrm{H}_{2}$ can be produced. The syngas's lower heating value may vary from $1.86 \mathrm{MJ} / \mathrm{Nm}^{3}$ to $4.5 \mathrm{MJ} / \mathrm{Nm}^{3}$ in the gasification with air and from $5.2 \mathrm{MJ} / \mathrm{Nm}^{3}$ to $7.5 \mathrm{MJ} / \mathrm{Nm}^{3}$ in the gasification with steam. The cold gas efficiency may vary from $16 \%$ to $41 \%$ in the gasification with air and from $37 \%$ to $60 \%$ in the gasification with steam. A sensitivity analysis was used considering the cold gas efficiency and the LHV, in order to select the best configuration process for the best quality syngas. The syngas quality was also assessed through the electrical efficiency and the cogeneration efficiency.

\subsection{Review Articles}

In addition to the original articles, two reviews were published in this special issue. Briefly, the first review treats Pellet Production from Woody and Non-Woody Feedstocks: A Review on Biomass Quality Evaluation by Rodolfo Picchio, Francesco Latterini, Rachele Venanzi, Walter Stefanoni, Alessandro Suardi, Damiano Tocci and Luigi Pari.

Forest and agricultural biomasses represent a notable fuel source and they are renewable and sustainable feedstock for energy production. Nowadays, many factors (economic, social and environmental) have greatly contributed to the increase of their consumption. Among these, pellet has a substantial importance with an increase in production and innovations, concerning both woody and non-woody biomass. This form of densified biomass can be composed of a broad spectrum of possible raw materials, and for this reason the assessment of its quality may be considered an important issue.

In this regard, worldwide research in the last decade produced a consistent number of scientific papers, and this review work is aimed to highlight the most interesting ones and to give the readers an overall view of the most current knowledge about this large and interesting topic. The authors focused on pellets from agricultural and forestry origin with a selection of papers from the last five years (2016-2020) and grouped them in four main topics: influence of different agro-forest management systems on pellet quality; analysis of pellets from pure feedstocks; influence of blending and binders on pellet quality; influence of pre- and post- treatments. A critical discussion on research that is missing, on future developments, and trends closed this work.

The other review is Revolutionizing towards Sustainable Agricultural Systems: The Role of Energy by Ilaria Zambon, Massimo Cecchini, Enrico Maria Mosconi and Andrea Colantoni. The purpose of this work was to increase the performances of primary sector focusing on bioeconomy and sustainability. The application of innovations is a progressive and integrated process. Knowing the governance and opening a dialogue with stakeholders is a fundamental step for innovation and development at national or international scale. However, when opposing normative guidelines for alternative systems of agriculture that arise, modernizations in agricultural and forestry may contribute to outlining more sustainable systems. Currently the primary sector, except for industrial agriculture, does not seem to develop adequately in terms of innovation. This work highlights the main innovations of recent years in the primary sector, including agriculture and forestry. In this sector, one of the main aids for pursuing adequate sustainable development is undoubtedly represented by energy. In this emerging framework, adequate technologies for concrete energy efficiency are needed. Moreover, energy sustainability itself is one of the most discussed issues currently. With this review we try to understand which innovations have actually been received by the primary sector, highlighting their limits and opportunities. 


\section{Conclusions}

In summary, the papers of the special issue represent some of the latest and most promising research results in this new and exciting field, which continues to make significant impact on real-world applications. We are confident that this special issue will stimulate further research in this area.

We thank all the authors for their contributions to this special issue.

Author Contributions: Conceptualization, A.C., M.C., D.M., A.M., R.P.; methodology, V.C., F.R., E.D.M., M.C., D.M., A.M., R.P., A.C.; data curation, M.V., A.C., V.C., R.P.; supervision, A.C. All authors have read and agreed to the published version of the manuscript.

Funding: Ministry for Education, University and Research (MIUR) according to the Italian Law 232/2016.

Acknowledgments: The special issue was partially supported by the Italian Ministry for Education, University and Research (MIUR) according to the Italian Law 232/2016 within the fund for the financing of universities "Departments of Excellence".

Conflicts of Interest: The authors declare no conflict of interest.

\section{References}

1. Villarini, M.; Marcantonio, V.; Colantoni, A.; Bocci, E. Sensitivity Analysis of Different Parameters on the Performance of a CHP Internal Combustion Engine System Fed by a Biomass Waste Gasifier. Energies 2019, 12, 688. [CrossRef]

2. Del Giudice, A.; Acampora, A.; Santangelo, E.; Pari, L.; Bergonzoli, S.; Guerriero, E.; Petracchini, F.; Torre, M.; Paolini, V.; Gallucci, F. Wood Chip Dryingthrough the Using of a Mobile Rotary Dryer. Energies 2019, 12, 1590. [CrossRef]

3. RajabiHamedani, S.; Kuppens, T.; Malina, R.; Bocci, E.; Colantoni, A.; Villarini, M. Life Cycle Assessment and Environmental Valuation of Biochar Production: Two Case Studies in Belgium. Energies 2019, 12, 2166. [CrossRef]

4. Colantoni, A.; Villarini, M.; Marcantonio, V.; Gallucci, F.; Cecchini, M. Performance Analysis of a Small-Scale ORC Trigeneration System Powered by the Combustion of Olive Pomace. Energies 2019, 12, 2279. [CrossRef]

5. Bulgakov, V.; Pascuzzi, S.; Anifantis, A.; Santoro, F. Oscillations Analysis of Front-Mounted Beet Topper Machine for Biomass Harvesting. Energies 2019, 12, 2774. [CrossRef]

6. Li, K.; Xue, W.; Mao, H.; Chen, X.; Jiang, H.; Tan, G. Optimizing the 3D Distributed Climate inside Greenhouses Using Multi-Objective Optimization Algorithms and Computer Fluid Dynamics. Energies 2019, 12, 2873. [CrossRef]

7. Civitarese, V.; Acampora, A.; Sperandio, G.; Assirelli, A.; Picchio, R. Production of Wood Pellets from Poplar Trees Managed as Coppices with Different Harvesting Cycles. Energies 2019, 12, 2973. [CrossRef]

8. Schweier, J.; Blagojević, B.; Venanzi, R.; Latterini, F.; Picchio, R. Sustainability Assessment of Alternative Strip Clear Cutting Operations for Wood Chip Production in Renaturalization Management of Pine Stands. Energies 2019, 12, 3306. [CrossRef]

9. Zambon, I.; Cecchini, M.; Mosconi, E.; Colantoni, A. Revolutionizing Towards Sustainable Agricultural Systems: The Role of Energy. Energies 2019, 12, 3659. [CrossRef]

10. Gallucci, F.; Liberatore, R.; Sapegno, L.; Volponi, E.; Venturini, P.; Rispoli, F.; Paris, E.; Carnevale, M.; Colantoni, A. Influence of Oxidant Agent on Syngas Composition: Gasification of Hazelnut Shells through an Updraft Reactor. Energies 2020, 13, 102. [CrossRef]

11. Terrosi, C.; Cacini, S.; Burchi, G.; Cutini, M.; Brambilla, M.; Bisaglia, C.; Massa, D.; Fedrizzi, M. Evaluation of Compressor Heat Pump for Root Zone Heating as an Alternative Heating Source for Leafy Vegetable Cultivation. Energies 2020, 13, 745. [CrossRef]

12. Pantaleo, A.; Villarini, M.; Colantoni, A.; Carlini, M.; Santoro, F.; RajabiHamedani, S. Techno-Economic Modeling of Biomass Pellet Routes: Feasibility in Italy. Energies 2020, 13, 1636. [CrossRef]

13. RajabiHamedani, S.; Villarini, M.; Colantoni, A.; Carlini, M.; Cecchini, M.; Santoro, F.; Pantaleo, A. Environmental and Economic Analysis of an Anaerobic Co-Digestion Power Plant Integrated with a Compost Plant. Energies 2020, 13, 2724. [CrossRef]

14. Picchio, R.; Latterini, F.; Venanzi, R.; Stefanoni, W.; Suardi, A.; Tocci, D.; Pari, L. Pellet Production from Woody and Non-Woody Feedstocks: A Review on Biomass Quality Evaluation. Energies 2020, 13, 2937. [CrossRef]

15. Bulgakov, V.; Pascuzzi, S.; Ivanovs, S.; Santoro, F.; Anifantis, A.; Ihnatiev, I. Performance Assessment of Front-Mounted Beet Topper Machine for Biomass Harvesting. Energies 2020, 13, 3524. [CrossRef] 
16. Zambon, I.; Colantoni, A.; Carlucci, M.; Morrow, N.; Sateriano, A.; Salvati, L. Land quality, sustainable development and environmental degradation in agricultural districts: A computational approach based on entropy indexes. Environ. Impact Assess. Rev. 2017, 64, 3746. [CrossRef]

17. Colantoni, A.; Marucci, A.; Monarca, D.; Pagniello, B.; Cecchini, M.; Bedini, R. The risk of musculoskeletal disorders due to repetitive movements of upper limbs for workers employed to vegetable grafting. J. Food Agric. Environ. 2012, 10, 14-18.

18. Monarca, D.; Colantoni, A.; Cecchini, M.; Longo, L.; Vecchione, L.; Carlini, M.; Manzo, A. Energy characterization and gasification of biomass derived by hazelnut cultivation: Analysis of produced syngas by gas chromatography. Math. Probl. Eng. 2012, 2012, 102914. [CrossRef]

19. Anifantis, A.S.; Colantoni, A.; Pascuzzi, S.; Santoro, F. Photovoltaic and hydrogen plant integrated with a gas heat pump for greenhouse heating: A mathematical study. Sustainability 2018, 10, 378. [CrossRef]

20. Marucci, A.; Monarca, D.; Cecchini, M.; Colantoni, A.; Cappuccini, A. The heat stress for workers employed in laying hens houses. J. Food Agric. Environ. 2013, 11, 20-24.

21. Di Giacinto, S.; Colantoni, A.; Cecchini, M.; Monarca, D.; Moscetti, R.; Massantini, R. Dairy production in restricted environment and safety for the workers. Ind. Aliment. 2012, 530, 5-12.

22. Marucci, A.; Pagniello, B.; Monarca, D.; Cecchini, M.; Colantoni, A.; Biondi, P. Heat stress suffered by workers employed in vegetable grafting in greenhouses. J. Food Agric. Environ. 2012, 2, 1117-1121.

23. Monarca, D.; Cecchini, M.; Colantoni, A. Plant for the Production of Chips and Pellet: Technical and Economic Aspects of an Case Study in the Central Italy; Springer: Berlin/Heidelberg, Germany, 2011; pp. 296-306.

24. Monarca, D.; Cecchini, M.; Colantoni, A.; Marucci, A. Feasibility of the Electric Energy Production through Gasification Processes of Biomass: Technical and Economic Aspects; Springer: Berlin, Germany, 2011; pp. 307-315.

Publisher's Note: MDPI stays neutral with regard to jurisdictional claims in published maps and institutional affiliations. 